\title{
DRIVERS' AGE, GENDER, DRIVING EXPERIENCE, AND AGGRESSIVENESS AS PREDICTORS OF AGGRESSIVE DRIVING BEHAVIOUR
}

\begin{abstract}
Recent years have seen a growing interest in the problem of aggressive driving. In the present study two demographic variables (gender and age), two non-psychological driving-experience related variables (annual mileage and legal driving experience in years) and aggressiveness as a personality trait (including behavioural and affective components) as psychological variable of individual differences were examined as potential predictors of aggressive driving. The aim of the study was to find out the best predictors of aggressive driving behaviour. The study was based on an online survey, and 228 vehicle drivers in Latvia participated in it. The questionnaire included eight-item Aggressive Driving Scale (Bone \& Mowen, 2006), short Latvian version of the Buss-Perry Aggression Questionnaire (AQ; Buss \& Perry, 1992), and questions gaining demographic and driving experience information. Gender, age and annual mileage predicted aggressive driving: being male, young and with higher annual driving exposure were associated with higher scores on aggressive driving. Dispositional aggressiveness due to anger component was a significant predictor of aggressive diving score. Physical aggression and hostility were unrelated to aggressive driving. Altogether, the predictors explained a total of $28 \%$ of the variance in aggressive driving behaviour. Findings show that dispositional aggressiveness, especially the anger component, as well as male gender, young age and higher annual mileage has a predictive validity in relation to aggressive driving. There is a need to extend the scope of potential dispositional predictors pertinent to driving aggression.
\end{abstract}

Keywords: age; aggressive driving behaviour; driving-related variables; gender; personality trait 'aggressiveness'

\section{INTRODUCTION}

There is evidence that in industrial societies driving is the most dangerous activity for the majority of people (James \& Nahl, 2000). In 2008, 316 people died as a result of traffic accidents on the roads of Latvia; 5408 people were injured (Cel̦u satiksmes negadījumu statistika Latvijā, 2009). The above numbers constitute one of the highest ratios per one million inhabitants in the European Union.

A traffic accident (TA) occurs as a result of interaction of the human factor, technical design of the vehicle and the road; nevertheless, the significance of the human factor accounts for approximately $90 \%$ of TAs (Evans, 1991).

Risky driving including aggressive driving is one of the likely causes of a TA which is why it is important to identify the factors that would allow explaining the inclination of an 
individual to deliberately drive in a risky and aggressive manner violating traffic rules (James \& Nahl, 2000).

\section{The Concept of Aggressive Driving}

Aggressive driving behaviour is commonly defined as "any behaviour intended to physically, emotionally, or psychologically harm another within the driving environment" (Hennessy \& Wiesenthal, 2001, p.661). This definition is in accord with the general definition of aggressive behaviour as "any form of behaviour directed toward the goal of harming or injuring another living being who is motivated to avoid such treatment" (Baron \& Richardson, 1994, p.7).

Most of the authors claim that it is necessary to differentiate between aggressive driving behaviour or mild driver aggression (e.g., horn honking or hand gestures) and driver violence where the intent is to harm another road user (e.g., fighting or purposeful contact) or "road rage" (Hennessy \& Wiesenthal, 2001; Tasca, 2000). Hennessy \& Wiesenthal (2001) set mild driver aggression and driver violence against assertive driving, i.e., driving in a risky and selfish manner, which may entail harm to other drivers, but that harm is accidental rather than purposeful. Similarly, Lawton et al. (1997), using the concept of aberrant driving behaviour, differentiate between hostile driving behaviours and violations, i.e., deliberate disregard for traffic rules. So, a more precise definition of aggressive driving would focus on deliberate and wilful driving behaviours that, while not intended to physically harm another road user, show disregard for their safety and well-being (Tasca, 2000), show little respect for the rules of the road and are associated with willingness to take risks (Lawton et al., 1997; Parker et al., 1992). These behaviours are motivated by impatience, annoyance, hostility and/or an attempt to save time. For example, according to Bone \& Mowen (2006) "aggressive driving occurs when the operator of a motor vehicle drives under the influence of impaired emotions, resulting in the imposition of one's own preferred level of risk on others" (Bone \& Mowen, 2006, p.454). Some authors define aggressive driving as willingness to take risks and display of little respect for the rules of the road (Lawton et al., 1997; Parker et al., 1992).

Leo Tasca (2000) offered a reviewed formal definition of aggressive driving behaviour, stating that a driving behaviour is aggressive if it is deliberate, likely to increase the risk of collision and is motivated by impatience, annoyance, hostility and/or an attempt to save time. Section 1494, Part 14, Clause 2 of the Latvian Administrative Violations Code defines aggressive driving in a similar manner, namely, aggressive driving is "...the driving of the vehicle in such a way, that a violation of the road traffic regulations is committed and a disruption is caused to the even flow of vehicles or other vehicle driver's interests are ignored..." (LAPK, 1984, 2005).

The specific behaviours, which constitute aggressive driving, would include: tailgating, weaving in and out of the traffic, improper passing (e.g., cutting in too close in front of vehicle being overtaken), passing on the road shoulder, improper lane changes (failure to signal), failure to yield the right of way to other road users, preventing other drivers form passing, running stop signs, running red lights, driving at speeds far in excess of the norm and unwillingness to extend cooperation to motorists unable to merge or change lanes due to traffic conditions (Tasca, 2000; James \& Nahl, 2000). Displays of annoyance and hostility which are not intended to physically harm other road users, but likely to intimidate, irritate, anger or provoke them may accompany these behaviours and serve as indicators of the underlying motivation and thus are commonly associated with aggressive driving. These behaviours would include: flashing headlights, sustained horn-honking, glaring at another driver to show disapproval, yelling and gesturing (Tasca, 2000; Bone \& Mowen, 2006). As one can see, aggressive driving comprises a 
range of specific actions at different levels of severity in terms of inflicted harm and potential to create dangerous traffic situations (Krahé, 2005).

Beyond documenting the extent to which drivers engage in different forms of aggressive or aberrant driving behaviour, research has moved toward analyzing personal and situational variables predicting differences in aggressive driving and examining the underlying psychological processes that lead to aggressive behaviour on the road (Krahé, 2005). In some studies several factors which increase the likelihood of aggressive driving behaviour have been suggested (see for review: Tasca, 2000). It was shown that drivers are more likely to engage in these behaviours if they are: relatively young, male, generally disposed to sensation-seeking or aggressiveness in other social situations, angry (possibly due to events unrelated to traffic situation), believe they possess superior driving skills, obstructed by unexpected traffic congestion and in traffic situations which confer anonymity and/or where escape is highly likely (Tasca, 2000). With respect to individual differences in aggressive driving, three variables have attracted particular research attention: gender, age and dispositional aggressiveness (Krahé, 2005).

\section{Gender and Aggressive Driving}

Official statistics reveal that men outnumber women by a wide margin in traffic violations and accident involvement. In addition, speeding and driving under the influence of alcohol were more common causes of lethal accidents in male than in female drivers (official statistical data can be found in CSDD, 2009). Similar tendencies are also annually observed in other countries of Europe (Özkan, 2006). Studies using self-reports of driving behaviour also suggest that gender is a predictor of aberrant driving behaviour. It was shown that aggressive driving and traffic violations are more common within men-drivers (e.g., Hennessy \& Wiesenthal, 2002; Áberg \& Rimmö, 1998). However, when aggressive driving is subdivided into mild driver aggression and driver violence, a more differentiated picture of the role of gender differences emerges. Hennessy and Wiesenthal (2001) found that men scored higher on a measure of driving violence than women, but that no gender differences emerged with respect to mild driver aggression. Parker et al. (2002) found that male drivers reacted more aggressively than female drivers when other drivers impeded their progress or showed inconsiderate and impatient driving behaviour.

\section{Age and Aggressive Driving}

Many researchers have come to a conclusion that irrespective of the gender young drivers are often more aggressive and risk-oriented then older ones (Lawton, Parker et al., 1997; Evans, 1991). Young drivers often drive recklessly and exceed speed limits to a great extent which, in its turn, significantly correlates with a high risk of TAs (Elander, West, \& French, 1993). Young male drivers show a disproportionate risk of accident involvement (Elander, West, \& French, 1993). The statistical data from many countries including those of Latvia show that the highest risk group are drivers aged 18 to 24, especially men under 20 (Cel̦u satiksmes negadījumu statistika Latvijā, 2009). According to official statistics in Latvia, traffic accidents rates' decline with age is explicit only in male-drivers subgroup, but in women subgroup differences in accident rates are quite even across all age groups with slightly bigger accident risk in the age from 18 to 25 years old (Celu satiksmes negadījumu statistika Latvijā, 2009). In accordance with these data Lajunen and Parker (2001) found that age was associated with a decrease in aggressive driver behaviour among their male but not among their female respondents.

\section{Driving Experience and Aggressive Driving}

There is scarce evidence for the relation between annual mileage and aggressive driving. Lajunen and Parker (2001) found annual mileage to be negatively related to driving aggression 
in women, but, in contrast, Krahé (2005) showed that aggressive driving behaviour by women increased as a function of annual mileage. Some researchers have proved that traffic safety is more connected with the drivers' behaviour than driving skills as it is less important what a driver is capable of doing as is what s/he chooses to do (for instance, Özkan, 2006).

\section{Aggressiveness and Aggressive Driving}

In addition to sex and age, which are demographic indicators of high risk groups for driving aggression, researchers examined psychological variables associated with stable individual differences in aggressive driving. Personality trait - aggressiveness, which refers to an individual's general tendency to show aggressive behaviour, is an obvious candidate (Krahé, 2005). A widespread conceptualization and measurement of dispositional aggressiveness was introduced by Buss and Perry (1992). They had identified two behavioural components, i.e., verbal and physical aggression, and two affective components i.e., anger and hostility, of dispositional aggressiveness. In one of the few studies applying the construct of dispositional aggressiveness to the area of driving aggression, Lajunen and Parker (2001) found that these components differently predicted men's and women's driving aggression in response to three types of angereliciting situations: impeding progress, reckless driving, and direct hostility. Krahé (2005) found that dispositional aggressiveness was a significant predictor of women's driving aggression. In addition, it was shown that the overall link between trait 'aggressiveness' and aggressive driving was due primarily to the physical aggression component of dispositional aggressiveness (Krahé, 2005) as conceptualized by Buss and Perry (1992).

\section{THE AIM OF THE STUDY}

To find out the best predictors of aggressive driving behaviour and to identify individual and combined predictive power of drivers' demographic variables, driving experience related variables and trait aggressiveness in relation to aggressive driving behaviour.

The main questions of the study are: Q1: How drivers' age, gender, annual mileage and aggressiveness is related to the aggressive driving? Q2: Which variables of drivers' individual differences could be better predictors of aggressive driving?

\section{METHOD}

\section{Participants and Measures}

The sample consisted of 228 (91 female and 137 male) car drivers aged between 20 and 64 years $(M=34, S D=9$ years $)$. The mean kilometres driven per year was $20929.80 \mathrm{~km}$ and mean duration of licence possession was 12.26 ( $\mathrm{SD}=8.16$, range from 2 to 39 years). The respondents, who had been recruited in a "snowball" fashion, participated in the study on an unpaid voluntary basis and filled out an on-line questionnaire containing the following parts:

1) A short Latvian version of the Buss-Perry Aggression Questionnaire (AQ; Buss \& Perry, 1992; translation made by Perepjolkina and Berzina in 2009) was employed to measure trait aggressiveness. This AQ version consists of 22 items addressing the trait aggressiveness in three components: physical aggression (8 items, e.g., "If somebody hits me, I hit back"); anger (8 items combined from original anger and verbal aggression subscales; sample item: "When people annoy me, I may tell them what I think of them"), and hostility (6 items, e.g., "I am sometimes eaten up with jealousy"). Responses were made on a five-point scale ranging from $0=$ not at all true to $4=$ very true.

2) Aggressive driving was measured by a Latvian version of eight-item Aggressive Driving Scale (Bone \& Mowen, 2006; translation made by Perepjolkina in 2009). Example items are: "Get angry at other drivers when in my car"; "Rapidly switched lanes in traffic to get 
to my destination fast". Participants were asked to indicate how often they committed each of the behaviours using a six-point scale ranging from $0=$ never to $5=$ very often.

3) In addition respondents were asked to indicate their sex, age, an average amount of $\mathrm{km}$ driven per year, and the duration of licence possession in years.

\section{Statistical analysis}

Statistical analysis was made using SPSS 17.0. First reliability (Cronbach's alpha) of the used measures was analysed, then descriptive statistics of all variables were computed for the total sample and for male and female subsamples separately. The differences between male and female average indices were analysed by the means of independent samples $t$-test. To analyze correlations between the scores of aggressive driving and other variables Spearman's rank correlation coefficient (rho) was used. In addition partial correlations were computed to measure the degree of association between aggressive driving and all other criterion variables (dispositional aggressiveness, physical aggression, anger, hostility, annual mileage, and duration of licence possession) with the effect of gender and age removed (controlling for gender and age). All correlations were first computed for the total sample and then for male and female subsamples separately. Finally, stepwise hierarchical regression analysis was made to find out better predictors of aggressive driving.

\section{RESULTS}

\section{Scale Reliabilities, Descriptive Statistics and Inter-correlations}

Scale reliabilities and descriptive statistics for the measures used in the study for the total sample and for male and female driver subsamples separately are presented in Table 1. All instruments had good or very good reliabilities.

The means for AQ and the measure of aggressive driving both had means at the lower end of the response scale. As it was expected and in consistence with previous findings (e.g., Khoza \& Potgieter, 2005; Áberg \& Rimmö, 1998; Lawton et al., 1997; Parker et al., 1992) male-drivers on average scored significantly higher on aggressive driving scale $(\mathrm{t}(228)=2.25, \mathrm{p}<0.05)$, as well as on dispositional aggressiveness $(\mathrm{t}(228)=4.53, \mathrm{p}<0.001)$ and on physical aggression subscale $(\mathrm{t}(228)=4.53, \mathrm{p}<0.001)($ see Table 1$)$. There were no statistically significant differences between male and female-drivers average scores on anger and hostility subscales.

Table 1. Scale Reliabilities, Descriptive Statistics and t-test Statistics

\begin{tabular}{|c|c|c|c|c|c|}
\hline \multirow{2}{*}{ Variables } & \multirow[b]{2}{*}{$\begin{array}{c}\text { Cronbach's } \\
\text { alpha }\end{array}$} & \multirow[b]{2}{*}{$\begin{array}{c}M(\mathrm{SD}) \\
(\mathrm{N}=228)\end{array}$} & \multirow{2}{*}{$\begin{array}{c}\mathrm{M} \\
\text { male- } \\
\text { drivers } \\
(\mathrm{n}=137)\end{array}$} & \multirow{2}{*}{$\begin{array}{c}\mathrm{M} \\
\text { female- } \\
\text { drivers } \\
(\mathrm{n}=91)\end{array}$} & \multirow[b]{2}{*}{$\mathrm{t}$} \\
\hline & & & & & \\
\hline 1. Aggressive driving & 0.78 & $9.68(4.94)$ & 11.03 & 7.64 & $5.37 * * *$ \\
\hline 2. Dispositional Aggressiveness & 0.93 & $22.80(14.26)$ & 24.51 & 20.22 & $2.25^{*}$ \\
\hline 2.1. Physical Aggression & 0.86 & $6.68(5.98)$ & 8.09 & 4.57 & $4.53 * * *$ \\
\hline 2.2. Anger & 0.89 & $9.64(6.26)$ & 9.69 & 9.58 & 0.12 \\
\hline 2.3. Hostility & 0.84 & $6.47(4.60)$ & 6.74 & 6.07 & 1.08 \\
\hline 3. Age & - & $34.25(9.18)$ & 33.85 & 34.86 & 0.81 \\
\hline 4. Annual Mileage & - & $\begin{array}{c}20929.80 \\
(2132929)\end{array}$ & 25211.79 & 143886.52 & $3.98 * * *$ \\
\hline 5. Duration of Licence Possession & - & $12.26(8.16)$ & 13.22 & 10.81 & $2.35 *$ \\
\hline
\end{tabular}

Note: $* \mathrm{p} \leq 0.05, * * * \mathrm{p} \leq 0.001 ; \mathrm{M}-$ mean, $\mathrm{SD}-$ standard deviation, $\mathrm{t}-$ independent samples $t$-test's score. 
The inter-correlations (zero-order and partial correlations) of the measures are displayed in Table 2. Substantial positive correlations were found between dispositional aggressiveness and aggressive driving, as well as between aggressive driving and two aspects of trait aggressiveness - physical aggression and anger. Substantial positive correlation was found also between annual mileage and aggressive driving score. All these correlations remain rather stable in magnitude and direction even after controlling drivers' age and gender. As it was expected and in line with previous findings and statistical data, substantial negative correlation was found between age and aggressive driving score.

Table 2. Spearman Correlations (above diagonal) and Partial Correlations (below diagonal)

of the Predictors and Criterion

\begin{tabular}{|c|c|c|c|c|c|c|c|c|c|}
\hline & $(1)$ & (2) & (3) & (4) & $(5)$ & (6) & (7) & $(8)$ & $(9)$ \\
\hline (1) Aggressive Driving & - & $.27 * *$ & $.34 * *$ & $.24 * *$ & .07 & $-.24 * *$ & $-.34 * *$ & $.25 * *$ & $-.13 *$ \\
\hline $\begin{array}{l}\text { (2) Dispositional } \\
\text { Aggressiveness }\end{array}$ & $.29 * *$ & - & $.76^{* *}$ & $.88 * *$ & $.73 * *$ & $-.15^{*}$ & $-.15^{*}$ & -.04 & -.08 \\
\hline (3) Physical Aggression & $.28^{* *}$ & $.86^{* *}$ & - & $.52 * *$ & $.33^{* *}$ & -.24 & $-.36^{* *}$ & .09 & -.11 \\
\hline (4) Anger & $.31^{* *}$ & $.90^{* *}$ & $.66^{* *}$ & - & $.54 * *$ & -.11 & .00 & -.05 & -.07 \\
\hline (5) Hostility & .12 & $.79 * *$ & $.50 * *$ & $.60 * *$ & - & .04 & -.04 & -.11 & .08 \\
\hline $\begin{array}{c}\text { (6) Age }(1=\text { male, } \\
2=\text { female })\end{array}$ & \multirow{2}{*}{\multicolumn{5}{|c|}{ Control Variables }} & - & .09 & -.01 & $.82 * *$ \\
\hline (7) Gender & & & & & & & - & $-.35^{* *}$ & -.09 \\
\hline (8) Annual Mileage & $.21 * *$ & -.03 & .03 & .00 & $-.13^{*}$ & \multirow{2}{*}{\multicolumn{2}{|c|}{$\begin{array}{l}\text { Control } \\
\text { Variables }\end{array}$}} & - & $.14^{*}$ \\
\hline $\begin{array}{l}\text { (9) Duration of Licence } \\
\text { Possession }\end{array}$ & .04 & .12 & .14 & .08 & .10 & & & .07 & - \\
\hline
\end{tabular}

Note: $* \leq 0.05, * * \mathrm{p} \leq 0.01$; control variables for partial correlations: age and gender; $\mathrm{N}=228$.

When analysing the correlations between the indicators of aggressive driving behaviour and driving experience, it has been established that there is a statistically significant positive correlation in the total sample between aggressive driving behaviour and annual mileage.

Partial correlation analysis made separately in male and female subsamples (see Table 3) revealed that after controlling age statistically significant positive correlations between aggressive driving and dispositional aggressiveness, physical aggression, anger, and annual mileage were found only in the male-drivers subsample. No statistically significant correlations between predictors and criterion variable were found in the female-drivers subsample after controlling the age variable. After controlling drivers' age no statistically significant correlations between aggressive driving and hostility, and duration of driving licence possession were found neither in male, nor female subsamples. These results are displayed in Table 3. 
Table 3. Partial Correlations between Predictors and Aggressive Driving in Combined Sample and in Male- and Female-drivers Samples Separately

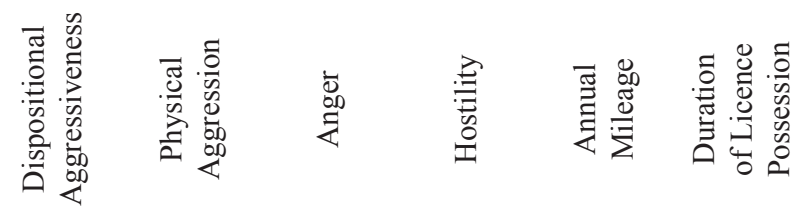

\begin{tabular}{clcccccc}
\hline & Combined sample & $.31^{* *}$ & $.34^{* *}$ & $.29 * *$ & $.13^{*}$ & $.27^{* *}$ & $.15^{*}$ \\
Aggressive & $(\mathrm{N}=228)$ & & & & & \\
Driving \# & Male-drivers $(\mathrm{N}=137)$ & $.33^{* *}$ & $.31^{* *}$ & $.36^{* *}$ & .16 & $.21^{*}$ & -.05 \\
& Female-drivers $(\mathrm{N}=91)$ & .17 & .20 & .19 & -.01 & .20 & .19 \\
\hline
\end{tabular}

Note: $* \mathrm{p} \leq 0.05, * * \mathrm{p} \leq 0.01 ; \#$ age is a control variable

The effect of the potential predictors of drivers' aggressive driving was examined in a stepwise hierarchical regression analysis. Hostility and duration of driving licence possession were excluded from potential predictors, due to non-correlation with criterion variable. The overall score of dispositional aggressiveness was not entered in the first model due to a high internal consistency across AQ subscales. The three non-psychological variables, age, gender and annual mileage, were entered in the first step, followed by two aspects of dispositional aggressiveness, physical aggression and anger, which were entered in the second and final step. The results are displayed in Table 4.

Table 4. Hierarchical Regression of Aggressive Driving on Physical Aggression, Anger, Gender, Age and Annual Mileage

\begin{tabular}{llll}
\hline Step & Variables Entered & Beta in step 1 & Beta in step 2 \\
\hline 1 & Gender $(1=$ male $2=$ female $)$ & $-0.28^{* * *}$ & $-0.24^{* * *}$ \\
& Age & $-0.20^{* *}$ & $-0.18^{* *}$ \\
& Annual mileage & $0.20^{* *}$ & $0.19^{* *}$ \\
2 & Physical aggression & & 0.12 \\
& Anger & & $0.21^{* *}$ \\
$\mathrm{R}^{2}$ & & 0.19 & 0.28 \\
Model F & & $17.30^{* * *}$ & $16.74^{* * *}$ \\
\hline
\end{tabular}

Note: $* \mathrm{p} \leq 0.05, * * \mathrm{p} \leq 0.01, * * * \mathrm{p} \leq 0.001$

All three non-psychological variables, gender, age and annual mileage, predicted aggressive driving: being male, young and with higher annual driving exposure were associated with higher scores on aggressive driving. Even though zero-order correlations between physical aggression and aggressive driving were significant $\left(\mathrm{r}_{o}=.28, \mathrm{p}<.001\right)$, only anger remained significant when two components of dispositional aggression were entered into the multiple regression model. Together these three variables explained $19 \%$ of the variance of aggressive driving score. Finally, there was a significant effect of anger on aggressive driving: the higher scores were on anger subscale, the higher aggressive driving score were obtained. Physical aggression was unrelated to aggressive diving. Altogether, the predictors explained a total of $28 \%$ of the variance in aggressive driving behaviour. 
A second stepwise multiple regression analysis was run, in which a composite score of dispositional aggressiveness was entered in Step 2. This analysis revealed that all four independent variables entered in the model predicted aggressive driving ( $\beta$ age $=-0.19, \mathrm{p}<0.01$, $\beta$ gender $=-0.24, \mathrm{p}<0.001, \beta$ annual mileage $=0.20, \mathrm{p}<0.01, \beta$ aggressiveness $=0.27, \mathrm{p}<0.01)$. Together these four variables explained $26 \%$ of the variance $(F(4)=19.51, p<0,001)$. In another words, results show, that the younger the respondents were, the more they drove per year and the more they reported to be generally disposed to aggressiveness in other social situations, the higher aggressive driving score they obtained. Male gender was associated with higher aggressive driving score as well.

\section{DISCUSSION}

The present study was aimed at identifying the best predictors of aggressive driving behaviour. Two demographical variables (gender and age), two non-psychological drivingexperience related variables (annual mileage and legal driving experience in years) and trait aggressiveness as a personality trait (including behavioural and affective components) were examined as potential predictors of aggressive driving. The results of correlation analysis showed a positive relationship between dispositional aggressiveness and aggressive driving, as well as between aggressive driving and two aspects of trait aggressiveness - physical aggression and anger. The correlation of aggressiveness and especially physical aggression and anger with aggressive driving can be explained by frustration-aggression theories (Berkowitz, 1989 etc.) and theories of weak impulse control (see for review Galovski et al., 2006), and they correspond to the results from previous research (for instance, Lajunen \& Parker, 2001; Malta \& Blanchard, 2004, as stated by Galovski et al., 2006). Even though it must be noted that the established correlations are weak, which means that aggressiveness as a personality trait is possibly not the most significant factor encouraging and giving explanation to aggressive driving. It is possible that the established correlation between aggressive driving behaviour and aggressiveness is mediated by other personality characteristics such as impulsiveness, sensation seeking, risk orientation, etc. (for instance Arnett, Offer, \& Fine, 1997), which were not analysed in this study.

Correlation analysis proves that age has a statistically significant negative correlation with aggressive driving behaviour in the entire sample as well as in the subsamples of both genders. A confirmation for a negative correlation between aggressive driving and age can be found both in statistical data (Ceḷu satiksmes negadījumu statistika Latvijā, 2009) and research papers (e.g., Lawton, Parker et al., 1997; Evans, 1991 etc.).

In consistence with previous findings (e.g., Áberg \& Rimmö, 1998; Khoza \& Potgieter, 2005; Lawton et al., 1997; Parker et al., 1992) it was shown that male-drivers scored significantly higher on aggressive driving scale, as well as on dispositional aggressiveness and on physical aggression subscale. There were no statistically significant differences between male and femaledrivers average scores on anger and hostility subscales.

When analysing the correlation between aggressive driving and indicators of driving experience, it has been noted that there is a statistically significant positive correlation between aggressive driving and the annual mileage in the entire sample and in male drivers' subsample, but not in female subsample. Nevertheless, partial correlation analysis revealed that established positive associations between annual mileage and aggressive driving remains stable after controlling age and gender variables. In contrast Lajunen and Parker's (2001) research has shown a negative correlation between the annual mileage and aggressive driving in the female drivers' sample, whereas Krahé (2005) established a contrary (positive) correlation in a female 
drivers' sample. This discrepancy in results possibly could be explained with cultural difference or some other factors which need additional explanation.

Two sequential stepwise regression analyses were made to find out the better predictor variables of aggressive driving. The results showed that aggressive driving behaviour decreased as a function of age and increased as a function of annual mileage. It means that the younger you are, and the more you drive per year, the more aggressive driving behaviour can be expected from you. Given the negative correlation between age and annual mileage, indicating that younger participants also had a higher annual mileage, it was reasoned that the positive link between annual mileage and driving aggression could have been a concealed age effect. However, the partial correlation between annual mileage and aggressive driving remained significant even after controlling for age. This finding is in accordance with finding made by Krahé (2005).

Being male predicted aggressive driving score as well. The correlation between male drivers and risky driving has been shown in many researches (e.g., Áberg \& Rimmö, 1998; Hennessy \& Wiesenthal, 2002; Özkan \& Lajunen, 2005) and found its conformation in the official statistics (CSDD, 2009).

Among the psychological variables, dispositional aggressiveness was a significant predictor of aggressive driving score, but this link between trait 'aggressiveness' and aggressive driving was due primarily to the anger component of dispositional aggressiveness as conceptualized by Buss and Perry (1992). The obtained results correspond to the definition of aggressive driving offered by Bone and Mowen (2006) stating that aggressive driving is the result of impaired emotions (anger, irritation). As a result of an aggressive mood and anger, the safety boundaries get lower and the subjectively acceptable risk limits rise (Wild, 1994). Our findings also corroborate previous evidence of a link between aggressiveness as a general disposition and driving aggression as a specific subtype of aggression (Lajunen \& Parker, 2001). It is interesting, that in accordance to the findings made by Krahé (2005) the overall link between trait 'aggressiveness' and women's aggressive driving was due primarily to the physical aggression component, but in our study the physical aggression component was not a significant predictor of aggressive driving neither in combined male- and female-driver's sample nor in male-drivers and female-drivers samples separately.

\section{Limitations of the study}

One of the limitations of this research is the use of self-reported questionnaires; however, it has been proved that the self-assessment results related to drivers' behaviour rather accurately represent the actual drivers' behaviour (for instance, West et al., 1993), especially in cases when surveys are conducted anonymously (Lajunen \& Summala, 2003), voluntarily and without a direct contact with an interviewer. All the conditions were met in this research, thus reducing the described problem. Another problem is the self-selected nature of the samples comprising only those individuals who volunteer to participate. Studies using unobtrusive observation of driving behaviour would circumvent this problem, but would, of course, incur other problems, such as difficulty in collecting information on relevant predictor variables (Krahé, 2005). Among respondents who agree to provide self-reports, the problem of systematic response biases needs to be considered, but it seems unlikely that self-presentational concerns elicited by the socially undesirable nature of aggressive driving had a differential effect on participants as a function of their dispositional aggressiveness. Nevertheless, it is important for future research to establish the congruence between self-reports and observational measures of driving behaviour to obtain a clearer picture of the individual characteristics that predict aggressive driving. 
Another limitation is related to the research sample: there were only Latvian-speaking respondents included into the sample who mostly reside in Riga or its suburbs; however, one must bear in mind that approximately $40 \%$ of all inhabitants in Latvia speak Russian and approximately $20 \%$ reside in rural areas which is why Russian-speaking inhabitants and drivers from the countryside and/or towns and villages should be included in future research.

Furthermore, there is a need to extend the scope of potential dispositional predictors pertinent to driving aggression (Ulleberg \& Rundmo, 2003).

\section{CONCLUSIONS}

After summarising the obtained results, it can be concluded that aggressiveness as a personality trait - especially the anger component - as well as male gender, young age and higher annual mileage has a predictive validity in relation to aggressive driving.

In future research it would be necessary to find out whether aggressiveness as a personality trait is connected with objective TA data (police data and data from insurance companies), as well as to extend the scope of potential dispositional predictors pertinent to driving aggression and TA.

\section{REFERENCES}

Áberg, L., \& Rimmö, P. A. (1998). Dimensions of aberrant driver behaviour. Ergonomics, 41, 39-56.

Arnett, J. J., Offer, D., \& Fine, M. A. (1997). Reckless driving in adolescence: "State" and "trait" factors. Accident Analysis and Prevention, 29, 57-63.

Baron, R. A., \& Richardson, D. R. (1994). Human aggression, $2^{\text {nd }}$ edition. New York: Plenum Press, 399.

Berkowitz, L. (1989). Frustration-aggression Hypothesis: Examination and reformulation. Psychological Bulletin, 106, 59-73.

Bone, A. \& Mowen, J. C. (2006). Identifying the traits of aggressive and distracted drivers: A hierarchical trait model approach. Journal of Consumer Behaviour, 5, 454-464.

Buss, A. H., \& Perry, M. (1992). The aggression questionnaire. Journal of Personality and Social Psychology, $63,452-459$.

Ceļu satiksmes negadījumu statistika Latvijā. 2009. gads [Road traffic accident statistics in Latvia] (2009). Riga: CSDD, 31 lpp. (in Latvian).

Elander, J., West, R, \& French, D. (1993). Behavioral correlates of individual differences in road-traffic crash risk: An examination method and findings. Psychological Bulleten, 113(2), 279-294.

Evans, L. (1991). Traffic safety and the driver. New York: Van Nostrand Reinhold, 404.

Galovski, Tara, E., Malta, Loretta, S., Blanchard, \& Edward, B. (2006). Theories of aggressive driving. In: Road rage: Assessment and treatment of the angry, aggressive driver. Washington, DC, US: American Psychological Association, pp. 27-44.

Hennessy, D. A., \& Wiesenthal, D. (2001). Gender, driver aggression, and driver violence: An applied evaluation. Sex Roles, 44, 661-676.

Hennessy, D. A., \& Wiesenthal, D. (2002). Aggression, violence, and vengeance among male and female drivers. Transportation Quarterly, 56, 65-75.

James, L. \& Nahl, D. (2000). Aggressive driving is emotionally impaired driving. Aggressive Driving Issues Conference, 16. Retrieved October 15, 2009, from http://www.aggressive.drivers.com. 
Khoza, V., Potgieter, J. (2005). Deviant driving behaviour: An epidemiological study. ACTA Criminologica, 18(2), 56-70.

Krahè, B. (2005) Predictors of women's aggressive driving behavior. Aggressive Behaviour, 31, 537-546.

Lajunen, T., \& Summala, H. (2003). Can we trust self-reports of driving? Effects of impression management on driver behaviour questionnaire responses. Transportation Research, F(6), Oxford: Elsevier, 97-107.

Lajunen, T., \& Parker D. (2001). Are aggressive people aggressive drivers? A study of the relationship between self-reported general aggressiveness, driver anger, and aggressive driving. Accident Analysis and Prevention, 33, 243-255.

Latvijas Administratīvo pārkāpumu kodekss. 1984. gada 7. decembra likums, 2005. gada 15. septembra redakcijā [The Latvian Administrative Violations Code]. Retrieved September 29, 2009, from http:// www.likumi.lv. (in Latvian).

Lawton, R., Parker, D., Manstead, A., \& Stradling, S. (1997). The role of affect in predicting social behaviours: The case of road traffic violations. Journal of Applied Social Psychology, 27, 1258-1276.

Özkan, T. (2006). The regional differences between countries in traffic safety: A cross-cultural study and Turkish case, Academic Dissertation. Research Reports, 37. University: University of Helsinki, 63.

Özkan, T., \& Lajunen, T. (2005). Why are there sex diferences in risky driving? The relationship between sex and gender-role on aggressive driving, traffic offences, and accident involvement among young Turkish drivers. Aggressive Behavior, 31, 547-558.

Parker, D., Lajunen, T., \& Summala, H. (2002). Anger and aggression among drivers in three European countries. Accident Analysis and Prevention, 34, 229-235.

Parker, D., Manstead, A., Stradling, S., Reason, J., \& Baxter, J. (1992) Intentions to commit driving violations: An application of the Theory of Planned Behavior. Journal of Applied Psychology, 77, 94-101.

Tasca, L. (2000). A review of the literature on aggressive driving research. Aggressive Driving Issues Conference, 26. Retrieved August 14, 2009, from http://www.aggressive.drivers.com/paperslist.html.

Ulleberg, P., \& Rundmo, T. (2003). Personality, attitudes and risk perception as predictors of risky driving behaviour among young drivers. Safety Science, 41, 427-43.

West, R., French, D., Kemp, R. \& Elander, J. (1993). Direct observation of driving, selfreports of driver behaviour and accident involvement. Ergonomics, 36. UK: Taylor \& Francis Group, 557-567.

Wild, G. J. S. (1994). Target risk. Dealing with the danger of death, disease and damage in everyday decisions. New York: PDE Publications, p.234. Retrieved September 9, 2009, from http://psyc.queensu.ca/.

Lecturer Mg. psych. Viktorija Perepjolkina

Riga Teacher Training and Educational Management Academy

Address: Sesku iela 7/2, dz. 61, Rīga, LV-1035

Phone: 26555038, fax: 67808034

E-mail: viktorija@rpiva.lv

Professor Dr. psych. Viesturs Rengge

University of Latvia, Faculty of Education, Psychology and Arts

Address: Madonas 25-39, Rīga, LV-1084

Phone: 67034020, fax: 67034018

E-mail: renge@lu.lv 